Gazi University
Journal of Science
http://dergipark.gov.tr/gujs

\title{
DFT Analysis of Mechanical and Dynamic Properties of CuBe
}

\author{
Ilknur KARS DURUKAN* (D), Yasemin OZTEKIN CIFTCI \\ Gazi University, Faculty of Science, Department of Physics, 06500, Ankara, Turkey \\ Highlights \\ - CuBe intermetallic compound is a ductile and soft material. \\ - The $\mathrm{CuBe}$ compound, which has a metallic property, is also compressible. \\ - Debye temperature is useful for thermoelectric and heat resistant material applications.
}

\begin{tabular}{l} 
Article Info \\
\hline \\
Received: 13 Apr 2021 \\
Accepted: 26 Oct 2021 \\
Keywords \\
\hline DFT \\
Intermetallic \\
Elastic constants \\
Anisotropy \\
Phonon
\end{tabular}

\begin{abstract}
In this study, we have presented a comprehensive theoretical calculation to analyze the mechanical, and dynamic properties of the CuBe with the Density Functional Theory (DFT). Hardness, plasticity, and Poisson's ratio are calculated. The ductile nature of the compound was demonstrated by mechanical properties. Also, the melting temperature $\left(\mathrm{T}_{\mathrm{m}}\right)$ of this material was $1581 \pm 300 \mathrm{~K}$. Debye temperature was found to be $489.17 \mathrm{~K}$, estimated from the acoustic velocity. The anisotropy properties of $\mathrm{CuBe}$ were evaluated in three dimensions and the presence of anisotropy in all other forms was revealed, except for Linner compression. The charge density plots show that the bonds between $\mathrm{Cu}-\mathrm{Be}$ are more ionic. As a final word, the absence of negative phonon frequencies of the $\mathrm{CuBe}$ intermetallic compound showed its dynamical stability.
\end{abstract}

\section{INTRODUCTION}

Intermetallic compounds have managed to attract the attention of scientists from different fields such as materials science, condensed matter physics, and geophysics for decades [1-5]. Intermetallic materials, which are formed by mixing two or more metals in certain proportions, have different crystal structures from the structures that compose them. Intermetallic compounds have more complex crystal structures than the crystal structure of the metallic elements that make up the compound. Thus, intermetallic compounds offer the potential to discover new materials. The unique properties of intermetallic compounds are due to the peculiar combination of electronics and crystal structure, which makes the chemical potentials of the elements not readily attainable in other compounds [6]. The widespread interest in intermetallic compounds in the scientific arena is due to their good thermal conductivity, high melting temperature, and resistance to environmental effects [7]. Among these intermetallic materials, Copper beryllium intermetallic alloys have long been used in the mining, gas, and petrochemical industries for their high strength, non-magnetic, corrosion resistance and excellent non-sparking properties in non-sparking tools, blow molds and plastic injection molding, complex-shaped springs, and sensors in a variety of applications [8]. CuBe is an intermetallic compound in the Pm3m space group (the B2 structure), belonging to the d group transition metal. $\mathrm{CuBe}$ combining the properties of copper $(\mathrm{Cu})$ and beryllium $(\mathrm{Be})$ is a hybrid material, the atomic order $\mathrm{Cu}(0,0,0)$ a and $\mathrm{Be}(0.5,0.5,0.5)$ a where a is the lattice parameter.

The static structural properties of beryllium were determined by Chou et al. using the Ab initio method [9]. In another study, the structural and electronic properties of beryllium were studied by Chou et al. using the same method [10]. The elastic and lattice parameters of $\mathrm{ScCu}, \mathrm{ScAg}, \mathrm{ScRu}, \mathrm{ScPd}$, and $\mathrm{ScRh}$ compounds were computed by Rajagopalan and Sundareswari using the FP - LAPW method [11]. Thermodynamic 
modeling of $\mathrm{Cu}-\mathrm{Be}$ alloys with the CALPHAD approach was performed by Liu et al [12]. In the study by Ullah et al., structural, optical, electronic, and elastic evaluation of $\mathrm{CuX}(\mathrm{X}=\mathrm{F}, \mathrm{Cl}, \mathrm{Br}$, I) copper halides were presented [13]. The electronic and elastic properties of the $\mathrm{BeCu}$ were examined by Jain et al. using the DFT method [14].

Recently, we have investigated structural, elastic, and electronic properties of $\mathrm{CuBe}$ using first-principles methods [15]. The structure was optimized and found to be mechanically stable in previous work [15]. Since the plastic deformation parameters, anisotropy properties, chemical bond nature, vibrational properties of the $\mathrm{CuBe}$ were not analyzed before, this study was performed to eliminate the deficiency in the literature. This article is presented as follows. The calculation method is summarized in Section 2 in MATERIAL METHOD. In Section 3, THE RESEARCH FINDINGS AND DISCUSSION section is included. In the last section, RESULTS is the part where the important findings of the present article are given.

\section{MATERIAL METHOD}

The Vienna Ab-initio Simulation Package [16-18] (VASP) using the density functional theory (DFT) was used to perform all calculations. The plane-wave basis sets with an energy cut-off $650 \mathrm{eV}$ and the $14 \times 14 \times 14$ Monkhorst and Pack [19] k-points in the Brillouin zone are used for the CuBe compound. To estimate the elastic properties are exploited by the stress-strain method [20]. Phonon calculation was performed using a $2 \times 2 \times 2$ supercell structure to determine the dynamic properties. Acoustic and optical phonon frequencies were determined using the PHONOPY code [21]. Mulliken atomic populations are calculated with the CASTEP code [22]. The three-dimensional representation of anisotropy properties is carried out by the ELAM code [23].

\section{THE RESEARCH FINDINGS AND DISCUSSION}

The elastic constants $(\mathrm{Cij})$ of $\mathrm{CuBe}$ were calculated in our previous study using the strain-stress method at ambient pressure [15]. Since $\mathrm{CuBe}$ compound has a cubic structure, it has three independent elastic constants $\left(\mathrm{C}_{11}, \mathrm{C}_{12}\right.$ and $\left.\mathrm{C}_{44}\right)$. $\mathrm{C}_{11}$ represents flexibility in length, while the other two represent flexibility in shape. As seen in Table 1 from Ref.[15], the elastic constants of $\mathrm{CuBe}$ in phase $\mathrm{B} 2$ are compatible with the Born criteria [24]. Elastic constants are the basic tool for understanding macroscopic mechanical properties connected to the basic physical properties of the crystal. The mechanical properties are calculated from Equations (1)-(5) [25-28] and their values are presented in Table 2

$$
\begin{aligned}
& B=\frac{1}{3}\left(C_{11}+2 C_{12}\right) \\
& G=\frac{1}{5}\left(C_{11}-C_{12}+3 C_{44}\right) \\
& E=\frac{9 B G}{3 B+G}
\end{aligned}
$$

$v=\frac{3 B-2 G}{2(3 B+G)}$

Table 1. Lattice parameter and elastic constants from Ref. [15]

$$
\begin{array}{lllll}
\mathrm{a}(\mathrm{A}) & \mathrm{C}_{11}(\mathrm{GPa}) & \mathrm{C}_{12} \text { (GPa) } & \mathrm{C}_{44}(\mathrm{GPa}) & \mathrm{B}(\mathrm{GPa})
\end{array}
$$




\begin{tabular}{|c|c|c|c|c|c|c|c|c|}
\hline CuBe & 2.695 & 174.0 & & 29.0 & 115.3 & & & \\
\hline & G(GPa) & E(GPa) & $B / G$ & $C_{12}-C_{44}$ & $\mathbf{v}$ & $\mathbf{A}^{\mathbf{Z}}$ & Hv(GPa) & $\mathrm{B} / \mathrm{C}_{44}$ \\
\hline CuBe & 60.8 & 159.8 & 2.36 & 13.7 & 0.31 & 5.124 & 5.063 & 1.24 \\
\hline $\mathrm{CuF}$ [12] & 31.42 & 77.30 & 1.51 & - & 0.23 & 0.63 & - & - \\
\hline $\mathrm{CuCl}[12]$ & 3.56 & 10.45 & 15.8 & - & 0.46 & -7.48 & - & - \\
\hline CuBr[12] & 28.92 & 72.79 & 1.73 & - & 0.25 & 2.26 & - & - \\
\hline $\mathrm{CuI}[12]$ & 11.11 & 30.70 & 3.90 & - & 0.38 & -28.4 & - & - \\
\hline
\end{tabular}

The value of the Bulk modulus (B) was found to be 144.0 GPa in our previous study [15]. The hardness of the crystal can be estimated from the Young (E) and Shear modulus (G). CuBe compound is not a rigid material since Young and shear modulus have not high values [29]. In the previous studies, the Shear and Young modulus of copper halides were very low value. It can be concluded that compounds with $\mathrm{Cu}$ are quite soft [13]. The brittleness of the compound was evaluated using the Paugh ratio (B/G). If $B / G<1.75$; a compound acts in a brittle nature otherwise ductile [30]. This ratio for $\mathrm{CuBe}$ is 2.36, indicating its ductile nature. Copper halides show ductile properties except for $\mathrm{CuF}$ and $\mathrm{CuBr}$ [13]. Ganesham et al. [31] found an association between ductility and the binding properties. Cauchy pressure $\left(\mathrm{C}_{12}-\mathrm{C}_{44}\right)$ also gives information about the hardness of the compound. If the $\left(\mathrm{C}_{12}-\mathrm{C}_{44}\right)$ is positive, the compound is ductile, otherwise, it is brittle [32]. Positive Cauchy pressure shows a metallic character [33]. When the value of the Poisson ratio $(v)$ is 0.5 , it is almost incompressible. But above this value, the material becomes incompressible [34]. In our study, the $v$, which determines that the CuBe compound is compressible, is $v \approx$ 0.31 for $\mathrm{CuBe}$ indicating that the $\mathrm{CuBe}$ compound has a metallic structure. Copper halides have compressible properties [13]. Elastic anisotropic factor $A^{Z}$, which is the parameter very important in engineering. $A^{Z}$ is used to determine the degree of anisotropy in a crystal. As shown in Table 2, for the $\mathrm{CuBe}$, anisotropy value is 5.124 , indicating that our compound is elastically anisotropic. Since the anisotropy values of copper halogens are smaller or larger than one, they show the anisotropic feature [13]. The Zener anisotropy index $A^{Z}$, the Chung-Buessem anisotropy index $A^{G}$, and the universal elastic anisotropy index $A^{U}$ for $\mathrm{CuBe}$ is calculated using Equations (6)-(8) [35-37]:

$A^{Z}=\frac{2 C_{44}}{C_{11}-C_{12}}$

$A^{G}=\frac{G_{V}-G_{R}}{G_{V}+G_{R}}$

$A^{U}=5 \frac{G_{V}}{G_{R}}+\frac{B_{V}}{B_{R}}-6 \geq 0$.

$B_{V}, B_{R}, G_{v}$ and $G_{R}$ are given as Equations (9)-(11)

$$
\begin{aligned}
& B=B_{V}=B_{R}=\frac{1}{3}\left(C_{11}+2 C_{12}\right) \\
& G_{V}=\frac{\left(C_{11}-C_{12}+3 C_{44}\right)}{5} \\
& G_{R}=\frac{5\left(C_{11}-C_{12}\right) C_{44}}{3\left(C_{11}-C_{12}\right)+4 C_{44}} .
\end{aligned}
$$

The crystal is considered elastically isotropic when the value of $A^{Z}$ is 1 and the value of $A^{G}$ and $A^{U}$ is zero. $A^{Z}$ value less than or greater than 1 indicates the degree of anisotropy. The deviation of $A^{U}$ from zero defines 
the degree of single-crystal anisotropic elastic properties. $A^{G}=1$ indicates that the elastic anisotropy is maximum. In this study, calculated $A^{Z}, A^{G}$, and $A^{U}$ values are found to be 5.12, 0.24 , and 3.15 , respectively. These calculated values show that $\mathrm{CuBe}$ is elastically anisotropic.

Hardness (Hv) is generally understood as how much a given solid resists both elastic and plastic deformations [38]. Vickers hardness was determined from Equation (12)

$H_{v}=2\left(\left(\frac{G}{B}\right)^{2} G\right)^{0.585}-3$

The obtained Vickers hardness value of $\mathrm{CuBe}$ was found as $5.063 \mathrm{GPa}$ showing that the compound is relatively soft. Soft material is called for the material if hardness is smaller than $10 \mathrm{GPa}[39,40]$. Plasticity, an important term in physics and materials science, is the irreversible shape changing of the solid material in response to applied forces and is the ability to undergo permanent deformation. The ratio of bulk modulus (B) to $\mathrm{C}_{44}$ is a measure of plasticity [41]. The plasticity value of the CuBe compound is 1.24 as given in Table 2. In engineering, plasticity defines the transition from elastic behavior to plastic behavior.

Debye temperature $\theta_{D}$ is a specific parameter and is associated with many physical properties of solid materials such as thermal expansion, heat capacity, acoustic velocity. It is related to the elastic constants. The $\theta_{D}$ value can be estimated by using the average sound velocity by the following Equation (13) [42]:

$\theta_{D}=\frac{h}{k_{B}}\left[\frac{3 n}{4 \pi}\left(\frac{N_{A} \rho}{M}\right)\right]^{\frac{1}{3}} V_{m}$

where $h$ is Planck's constant, $k_{B}$ is Boltzmann's constant, $n$ is the number of atoms in the cell, $N_{A}$ is Avogadro's number, $M$ is the molecule mass, $\rho$ is the density, and $V_{m}$ is the average isotropic sound velocity which can be expressed as [42]:

$V_{m}=\left[\frac{1}{3}\left(\frac{1}{V_{l}^{3}}+\frac{2}{V_{t}^{3}}\right)\right]^{-1 / 3}$.

Here, the longitudinal $V_{l}$ and transverse $V_{t}$ sound velocities can be obtained as follows [43]:

$V_{l}=\sqrt{\frac{3 B+4 G}{3 \rho}}$

$V_{t}=\sqrt{\frac{G}{\rho}}$.

The Debye, average longitudinal $(\mathrm{v} 1(\mathrm{~m} / \mathrm{s}))$ and transverse elastic wave velocities $(\mathrm{vt}(\mathrm{m} / \mathrm{s}))$ and average sound velocity $(\mathrm{vm}(\mathrm{m} / \mathrm{s}))$ were calculated from elastic constants. The obtained results are listed in Table 3 .

Table 3. Melting temperature Tm(K), velocities of sound $(\mathrm{m} / \mathrm{s})$ and Debye temperature $\theta_{D}(K)$ for CuBe

\begin{tabular}{|lccccc|}
\hline & $\mathbf{T m} \pm \mathbf{3 0 0}$ & $\mathbf{V l}$ & $\mathbf{V t}$ & $\mathbf{V m}$ & $\boldsymbol{\theta}_{\boldsymbol{D}}$ \\
\hline CuBe & 1581.34 & 3142.81 & 3142.81 & 3517.16 & 489.176 \\
& & & & & \\
\hline CuBr [41] & - & - & - & - & 301.361 \\
\hline CuCl [41] & - & - & - & - & 376.019 \\
\hline
\end{tabular}

The Debye temperature was found to be $489.17 \mathrm{~K}$, calculated from the elastic constants using Equation (7). To analyze the result, we compared with other copper alloys, such as $\mathrm{CuBr}(301 \mathrm{~K})$ and $\mathrm{CuCl}(376 \mathrm{~K})$ [44]. Our obtained Debye temperature for $\mathrm{CuBe}$ is higher than those of $\mathrm{CuBr}$ and $\mathrm{CuCl}$ indicating that $\mathrm{CuBe}$ is harder than $\mathrm{CuBr}$ and $\mathrm{CuCl}$.

The melting temperature $(\mathrm{Tm})$ of this material was determined using the elastic constant $\left(\mathrm{C}_{11}\right)$ by the following Equation (17) [45-47]. The calculated value is given in Table 3 
$T_{m}=\left[553 \mathrm{~K}+5.91 \frac{\mathrm{K}}{\mathrm{GPa}} x C_{11}\right] \pm 300 \mathrm{~K}$.

The propagation velocity of $\mathrm{CuBe}$, which has a cubic structure, along different crystal directions of longitudinal and transverse waves can be calculated by the elastic constants $C_{\mathrm{ij}}$ [48] and given Table 4 . v1 is the largest of longitudinal wave velocities which is a quasi-longitudinal wave. In a pure longitudinal wave, (100) direction, the direction of the particle vibration is perpendicular to the forward direction of the wave, whereas, for the semi-longitudinal wave, (110) and (111) directions, the velocity component will be generated in other directions. The velocities for v3, v4, and v5 have different velocities; transverse waves, which are formed by the degeneracy split into $v 4$ and v5. Based on the above-mentioned reasons, we can conclude that it is anisotropy in this direction.

Table 4. Relation of velocity $(\mathrm{m} / \mathrm{s})$ to elastic constants for various propagation modes

\begin{tabular}{|ccc|}
\hline Orientation & propagation modes & Velocity \\
\hline $\mathbf{( 1 0 0 )}$ & Longitudinal & 5317 \\
\hline $\mathbf{( 1 0 0 )}$ & Transverse & 4328 \\
\hline $\mathbf{( 1 1 0 )}$ & Longitudinal & 6583 \\
\hline $\mathbf{( 1 1 0 )}$ & Transverse & 4328 \\
\hline $\mathbf{( 1 1 0 )}$ & Transverse & 1912 \\
\hline $\mathbf{( 1 1 1})$ & Longitudinal & 6955 \\
\hline $\mathbf{( 1 1 1})$ & Transverse & 2946 \\
\hline
\end{tabular}

A critical feature that determines the area of use of the material is the degree of elastic anisotropy [49]. While the crystalline isotropic elastic properties can be easily represented, anisotropic properties can be quite difficult to visualize the variation of orientation of properties such as Young's modulus or Poisson's ratio. The ELAM (Elastic Anisotropy Measurements) code performs the necessary tensor operations such as inversion, rotation, diagonalization and visualizes a 3D model of the anisotropy of an elastic property. Once this critical property is known, the strength of the material can be evaluated for any application. [5052]. The anisotropy properties of $\mathrm{CuBe}$ were analyzed in detail. ELAM code was used for anisotropy calculations. The absence of sphericity indicates the degree of anisotropy in three-dimensional physical properties. In Figure 1 and Table 5, the presence of anisotropy in all other forms except Linner compression was determined. 

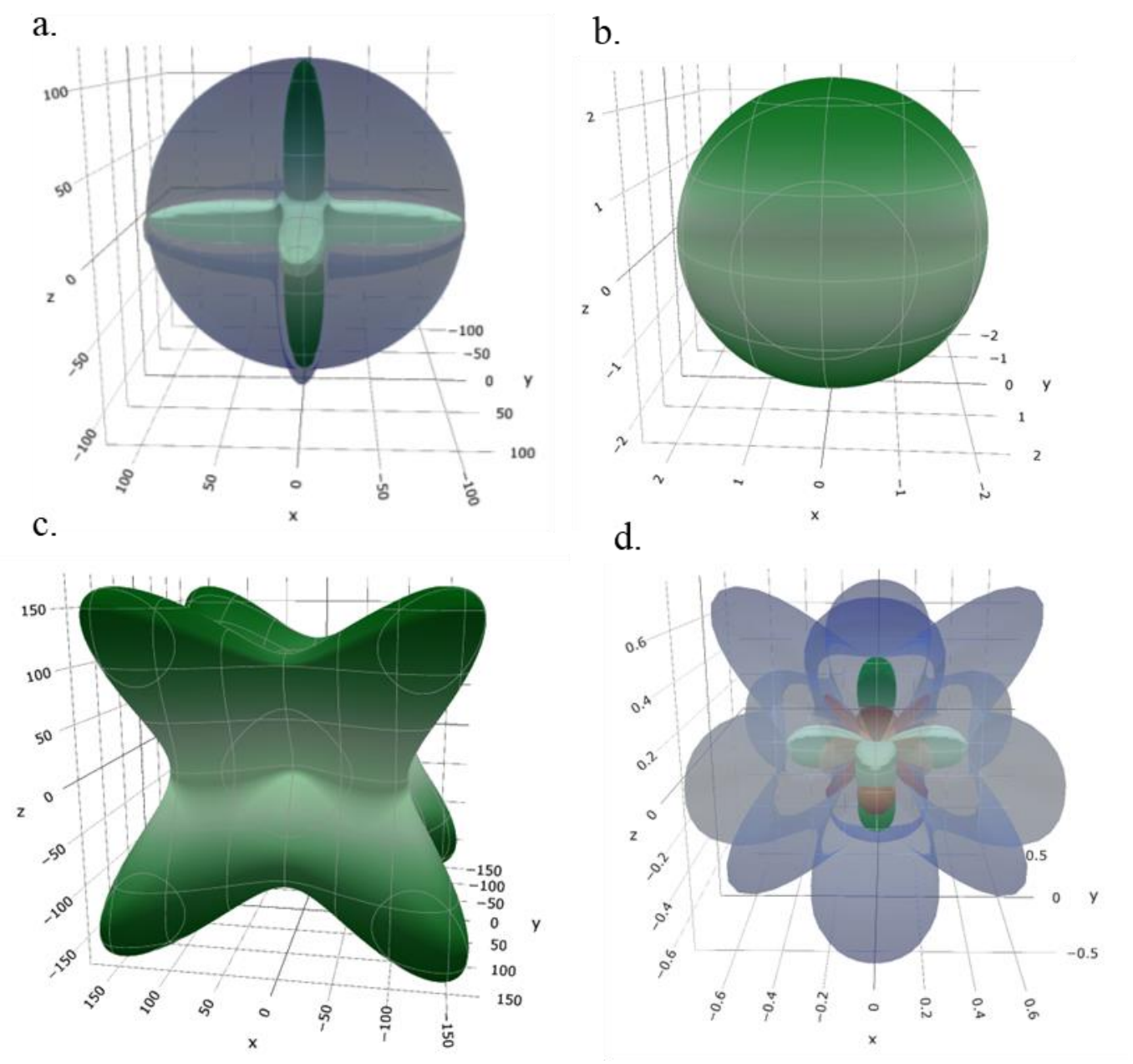

Figure 1. Three-dimensional elastic anisotropy; (a) Shear modulus $(G)$, (b) Linear compressibility $(\beta)$, (c) Young's modulus( $E)$, (d)Poisson's ratio (U)

Table 5. Lower and upper values of elastic modulus of the CuBe compound

\begin{tabular}{|c|c|c|c|c|c|c|c|c|}
\hline \multirow{3}{*}{$\begin{array}{l}\text { Compound } \\
\mathrm{CuBe}\end{array}$} & \multicolumn{2}{|c|}{$\mathrm{G}(\mathrm{GPa})$} & \multicolumn{2}{|c|}{$\beta\left(\mathrm{TPa}^{-1}\right)$} & \multicolumn{2}{|c|}{$\mathrm{E}(\mathrm{GPa})$} & \multicolumn{2}{|l|}{$v$} \\
\hline & $\mathrm{G}_{\min }$ & $\mathrm{G}_{\max }$ & $\beta_{\min }$ & $\beta_{\max }$ & $E_{\min }$ & $E_{\max }$ & $U_{\min }$ & $U_{\max }$ \\
\hline & 22.5 & 115.3 & 2.31 & 2.31 & 64.158 & 273.03 & -0.34 & 0.99 \\
\hline
\end{tabular}

Charge density helps to analyze the bond character between atoms. The properties of the bonding structure between atoms can be understood by considering electro-negativity and charge transfer between atoms. The value of electro-negativity of $\mathrm{Cu}$, and $\mathrm{Be}$ are 1.9 , and 1.57 respectively. When the electronegativity of the two atoms is different, it confirms that the electron density is high in the atom with high electronegativity and the presence of covalent bonds. Also, this situation is seen in Figure 2. Sphericity in charge density is the sign of the ionic bond between $\mathrm{Cu}$ and $\mathrm{Be}$ atoms. Also, some electron sharing in $\mathrm{Cu}$ atoms shows covalent bonding like the bonding in copper as seen Ref [13]. Consequently, bonding in $\mathrm{CuBe}$ has a mixing of ionic and covalent bonding. 


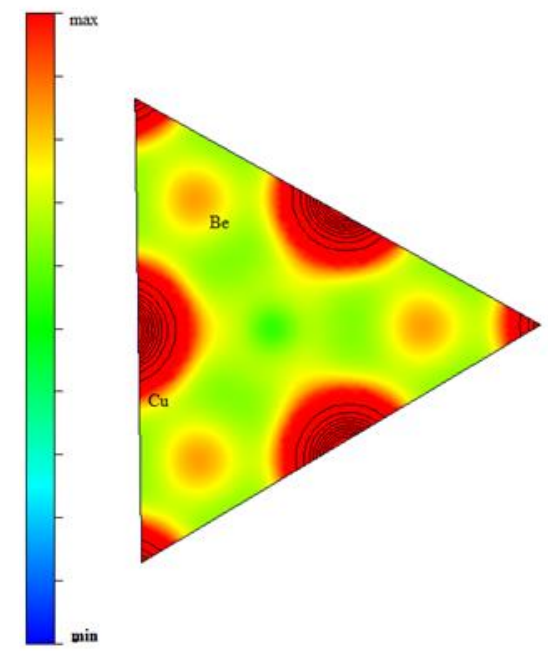

Figure 2. 2D charge density map for (111) plane for $\mathrm{CuBe}$

To analyze the binding nature of the molecules and charge transfer in detail, the evaluation of Mulliken atom populations was made [53] and the values are presented in Table 6. According to the Mulliken charge analysis, the electronic charges of $\mathrm{Cu}$ and $\mathrm{Be}$ atoms for the $\mathrm{CuBe}$ compound are $0.08 \mathrm{e}$ and $-0.08 \mathrm{e}$, respectively. This shows that there is a charge transfer from the $\mathrm{Cu}$ atom to $\mathrm{Be}$ atom, there is an ionic bond between the two atoms. We can calculate the ionicity of any material using the following Equation (12) [54]

$F_{h}=1-e^{-\left|P_{c}-P\right| / P}$

where $\mathrm{P}$ is the bond overlap population, $\mathrm{P}_{\mathrm{C}}$ is the bond overlap population in a pure covalent and the value of $\mathrm{P}_{\mathrm{C}}$ is one for the covalent crystal. When the value of $\mathrm{F}_{\mathrm{h}}$ is zero and one, it indicates the nature of the covalent and ionic bond, respectively. As a result, according to the data in Table 6, the bonds between $\mathrm{Cu}-$ Be showed covalent nature. Therefore, the bond in $\mathrm{CuBe}$ is the mixing form of covalent and ionic bonding together.

Table 6. Population analysis of CuBe compound

\begin{tabular}{|lcccccccccc|}
\hline \multicolumn{10}{|c|}{ Mulliken Atomic Populations } \\
& Atoms & $\mathrm{S}$ & $\mathrm{p}$ & $\mathrm{d}$ & $\mathrm{f}$ & Total & Charge & Bond & $\mathrm{F}_{\mathrm{h}}$ & Lengths \\
\hline $\mathrm{CuBe}$ & $\mathrm{Cu}$ & 0.4 & 1 & 9.6 & 0 & 10.9 & 0.08 & $\mathrm{Cu}-\mathrm{Be}$ & 0.06 & 2.3694 \\
& $\mathrm{Be}$ & 0.4 & 1.7 & 0 & 0 & 2.08 & -0.08 & & & \\
& & & & & & & & & & \\
\hline
\end{tabular}

Phonon frequencies of CuBe were calculated using the PHONOPY code $[21,55]$. Phonopy is an opensource code for phonons- based calculations. It has been described the dynamical properties of materials at finite temperature in this code. Phonon dispersion curves for the $\mathrm{CuBe}$ compound are shown in Figure 3. High symmetry-oriented phonon dispersion curves were calculated using 2 × 2 × 2 supercells. High symmetry points $\Gamma \mathrm{X}, \mathrm{XL}, \mathrm{L} \Gamma$, and $\Gamma \mathrm{L}$ were used for the $\mathrm{B} 2(\mathrm{CsCl})$ structure for the phonon distribution curve. The absence of negative phonon frequency in the Brillouin region confirms dynamic stability. Since the compound has two atoms, the phonon dispersion curves form six phonon branches, that three of these branches are acoustic, while the others are optical. The masses of $\mathrm{Cu}$ and $\mathrm{Be}$ are $63.546 \mathrm{akb}$ and $9.012 \mathrm{akb}$, respectively. Because the mass difference between the two atoms is so high, there is a large bandgap between the optical and acoustic region [56]. The corresponding partial density of phonon states is shown to the right of Figure 3. From PDOS, $\mathrm{Cu}$ atoms in the region between 0-6 THz contributed more to the acoustic modes. Modes larger than $12 \mathrm{THz}$ modes are mostly detected by vibrations of Be atoms. 


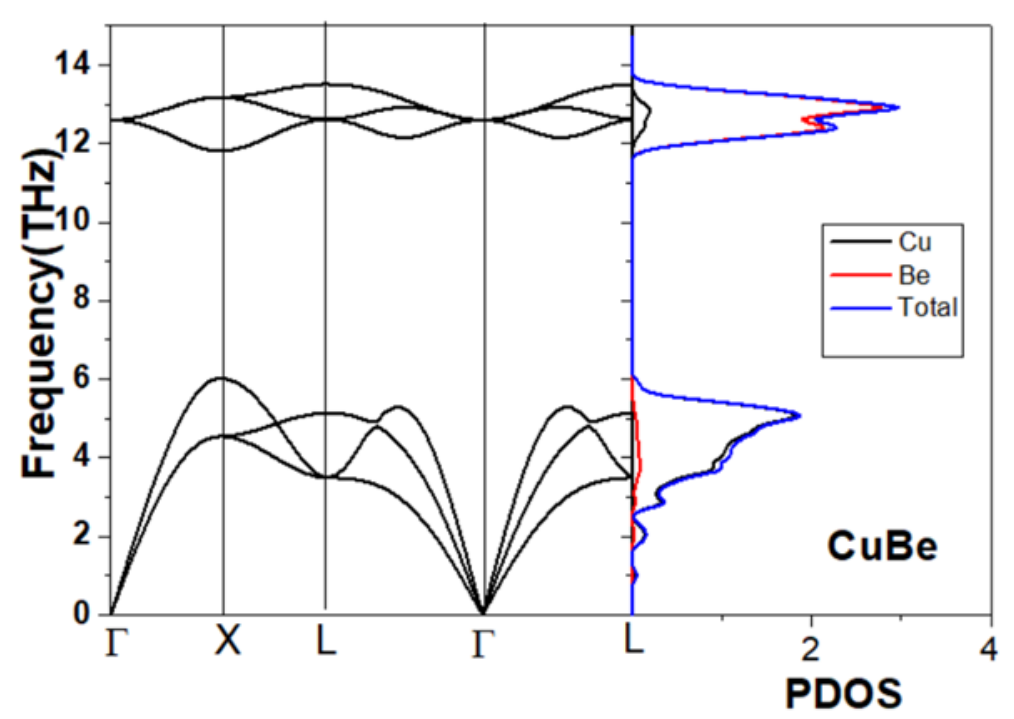

Figure 3. Phonon dispersion curves and partial PDOS of the CuBe compound

\section{RESULTS}

Mechanical, elastic anisotropy, dynamic properties, Debye temperature, and acoustic wave velocities in different directions are calculated using ab initio techniques. Our results have shown that $\mathrm{CuBe}$ is a ductile and soft material. The $\mathrm{CuBe}$ compound, which has a metallic property, is also compressible. Vickers hardness and Poisson ratio are also calculated by determining the bulk and shear modulus. The plasticity value of the CuBe compound is obtained as 1.24. The calculated Debye temperature is $489 \mathrm{~K}$ which was obtained by elastic constants. Knowing the Debye temperature is useful for thermoelectric and heat resistant material applications, as well as for future thermoelectric materials development. Acoustic wave velocities were analyzed in different directions. For a detailed analysis of the anisotropy properties, anisotropy plots of the mechanical properties were drawn to conclude that the elasticity of $\mathrm{CuBe}$ was highly anisotropic. The absence of imaginary frequency phonon in the Brillion region of the compound crystallized in the B2 structure showed that it was dynamically stable. The comprehensive results in this article serve as the basis for future experimental studies.

\section{CONFLICTS OF INTEREST}

No conflict of interest was declared by the authors.

\section{ACKNOWLEDGEMENT}

The paper is presented as an oral presentation in 1st International April 23 Scientific Studies Congress 20-23 April 2019 in Ankara, Turkey.

\section{REFERENCES}

[1] Furukawa, S., Komatsu, T., "Intermetallic Compounds: promising inorganic materials for wellstructured and electronically modified reaction environments for efficient catalysis", ACS Catalysis, 7: 735-765, (2017).

[2] Dasgupta, A., Rioux, R. M., "Intermetallics in catalysis: an exciting subset of multimetallic catalysts", Catalysis Today, 330: 2-15, (2019).

[3] Marakatti, V. S., Peter, S. C., "Synthetically tuned electronic and geometrical properties of intermetallic compounds as effective heterogeneous catalysts", Progress in Solid State Chemistry, 52: 1-30, (2018). 
[4] Rößner, L., Armbrüster, M., "Electrochemical energy conversion on intermetallic compounds a review", ACS Catalysis, 9: 2018-2062, (2019).

[5] Armbrüster, M., Schlögl, R., Grin, Y., "Intermetallic compounds in heterogeneous catalysis a quickly developing field", Science and Technology of Advanced Materials, 15: 034803, (2014).

[6] Armbrüster, M., "Intermetallic compounds in catalysis - a versatile class of materials meets interesting challenges", Science and Technology of Advanced Materials, 21:1, 303-322, (2020).

[7] Jain, E., Pagare, G., Dubey, S., and Sanyal, S. P., "Phonon and Thermodynamical Properties of CuSc: A DFT study", AIP Conference Proceedings, 1953: 110033, (2018).

[8] Huang, X., Xie, G., Liu, X., Fu, H., Shao, L., Hao, Z., "The influence of precipitation transformation on Young's modulus and strengthening mechanism of a $\mathrm{Cu}-\mathrm{Be}$ binary alloy", Materials Science \& Engineering A, 772: 138592, (2020).

[9] Chou, M. Y., Lam Pui, K., Marvin, L., "Ab initio calculation of the static structural properties of Be", Cohen. Solid State Communucations, 42: 861-863, (1982).

[10] Chou, M. Y., Lam Pui, K., Marvin, L., "Ab initio study of structural and electronic properties of beryllium”, Physical Review B, 28: 4179-4185, (1983).

[11] Rajagopalan, M., Sundareswari, M., "First-principles study of elastic properties of $\mathrm{ScX}(\mathrm{X}=\mathrm{Ag}, \mathrm{Cu}$, Pd, Ru and Rh) compounds", AIP Conference Proceedings, Manipal, India, 1349: 801- 802, (2010).

[12] Liu, Y., Sundman, B., Du, Y., Wang, J., Liu, S., Ping Gong, W., Zhang, C., "A stepwise thermodynamic modeling of the phase diagram for the $\mathrm{Cu}-\mathrm{Be}$ system", Journal of Materials Science, 53: 3756-3766, (2018).

[13] Ullah, H., Reshak, A. H., Inayat, K., Ali, R., Murtaza, G., At, S., Ud Din, H., Alahmed, Z., Sheraz, S., "Structural, elastic, optoelectronic and optical properties of $\mathrm{CuX}(\mathrm{X}=\mathrm{F}, \mathrm{Cl}, \mathrm{Br}, \mathrm{I})$ : A DFT study", Journal of Optoelectronics and Advanced Materials, 16: 1493 - 1502, (2014).

[14] Jain, E., Pagare, G., and Chouhan, S. S., "Full Potential Linearized Augmented Plane Wave (FPLAPW) Study of Intermetallic Compound: $\mathrm{BeCu}$ ", International Journal of Advancement in Electronics and Computer Engineering, 3: 306-309, (2014).

[15] Kars Durukan, İ., Oztekin Ciftci, Y., "Theoretical Study of Structural, Elastic Anisotropy, Electronic, and Vibrational Propertıes of CuBe Compound", 1. Uluslararası 23 Nisan Multidisipliner Çalışmalar Kongresi, Ankara, 152-156, (2019).

[16] Kresse, G., Hafner, J., “Ab initio molecular dynamics for liquid metals”, Physical Review B, 47: 558, (1993).

[17] Kresse, G., Hafner, J., "Ab initio molecular-dynamics simulation of the liquid-metal-amorphoussemiconductor transition in germanium", Physical Review B, 49: 14251, (1994).

[18] Kresse, G., Furthmuller, J., "Efficiency of ab-initio total energy calculations for metals and semiconductors using a plane-wave basis set", Computational Materials Science, 6: 15, (1996).

[19] Page, L., Saxe, P., "Symmetry-general least-squares extraction of elastic data for strained materials from ab initio calculations of stress", Physical Review B, 65: 104104, (2002). 
[20] Mehl, M. J., Osburn, J. E., Papaconstantopoulos, D. A., Klein, B. M, "Structural properties of ordered high-melting-temperature intermetallic alloys from first-principles total-energy calculations", Physical Review B, 41: 10311, (1990).

[21] Toga, A., Oba, F., Tanaka, I., "First-principles calculations of the ferroelastic transition between rutile-type and $\mathrm{CaCl} 2$-type $\mathrm{SiO} 2$ at high pressures", Physical Review B, 78: 134106- 1-9, (2008).

[22] Shi, D. M., Wen, B., Melnik, R., Yao, S., Li, T., "First principles studies of Al-Ni intermetallic compounds", Journal of Solid State Chemistry, 182: 2664-2669, (2009).

[23] Marmier, A., Lethbridge, Z. A. D., Walton, R. I., Smith, C.W., Parker, S.C., Evans, K.E., "ElAM: A computer program for the analysis and representation of anisotropic elastic properties", Computer Physics Communications, 181: 2102, (2010).

[24] Born, M., Huang, K., "Dynamical Theory of Crystal Lattices”, Oxford: Clarendon, (1954).

[25] Evecen, M., Ciftci, Y. O., "Theoretical investigation of the electronic structure, elastic, dynamic properties of intermetallic compound NiBe under pressure", The European Physical Journal B, 94: 1, (2021).

[26] Hill, R., "The Elastic Behaviour of a Crystalline Aggregate", Proceedings of the Physical Society, Section A, 65: 349, (1952).

[27] Zhang, L., Wang, X., Cheng, Z., "Electronic, magnetic, mechanical, half-metallic and highly dispersive zero-gap half-metallic properties of rare-earth-element-based quaternary Heusler compounds", Journal of Alloys and Compounds, 718: 63, (2017).

[28] Chen, X. Q, Niu, H., Li, D., Li, Y., "Modeling Hardness of Polycrystalline Materials and Bulk Metallic Glasses", Intermetallics, 19: 1275, (2011).

[29] Kars Durukan, I., Oztekin Ciftci, Y., "Anisotropic Elastic, Electronic and Vibrational Properties of the Semiconductor $\operatorname{AgScX}(X=\mathrm{Ge}, \mathrm{C})$ Compounds", Journal of Electronic Materials, 49: 1849-1856, (2020).

[30] Pugh, S. F., "XCII. Relations between the elastic moduli and the plastic properties of polycrystalline pure metals", Philosophical Magazine, 45: 823-843, (1954).

[31] Ganeshan, S., Shang, S. L., Zhang, H., Wang, Y., Mantina, M., Liu, Z. K., "Elastic constants of binary Mg compounds from first-principles calculations", Intermetallics, 17: 313-318, (2009).

[32] Shinde, S. M., Gupta, S. D., Gupta, S. K., Jha, P. K., "Lattice dynamics and thermodynamical study of yttrium monochalcogenides", Computational Materials Science, 92: 69-75, (2014).

[33] Pettifor, D. G., "Theoretical predictions of structure and related properties of intermetallics", Materials Science and Technology, 8: 345, (1992).

[34] Mott, P. H., Dorgan, J. R., Roland, C. M., "The bulk modulus and Poisson's ratio of "incompressible" materials", Journal of Sound and Vibrations, 312: 572-575, (2008).

[35] Spoor, P., Maynard J., Kortan, A., "Elastic isotropy and anisotropy in quasicrystalline and cubic AlCuLi", Physical Review Letters, 75: 3462, (1995).

[36] Ranganathan, S. I., Ostoja-Starzewski, M., "Universal elastic anisotropy index", Physical Review Letters, 101: 055504, (2008). 
[37] Chung, D., Buessem, W., "The elastic anisotropy of crystals”, Journal of Applied Physics, 38: 2010, (1967).

[38] Simunek, A., Vackar, J., "Hardness of covalent and ionic crystals: First-Principle Calculations", Physical Review Letters, 96: 085501, (2006).

[39] Zhang, M., Lu, M., Du, Y., Gao, L., Lu, C., Liu, H., "Hardness of FeB4: Density functional theory investigation", The Journal of Chemical Physics, 140: 174505, (2014).

[40] Kars Durukan, İ., Oztekin Ciftci, Y., "First-principles calculations of vibrational and optical properties of half-Heusler NaScSi”, Indian Journal of Physics, 94: 1-10, (2020).

[41] Vitos, L., Korzhavyi, P. A., Johansson, B., "Stainless steel optimization from quantum mechanical calculations", Nature Materials, 2: 25, (2003).

[42] Anderson, O. L., "A simplified method for calculating the debye temperature from elastic constants", Journal of Physics and Chemistry of Solids, 24: 909, (1963).

[43] Schreiber, E., Anderson, O. L., Soga, N., "Elastic Constants and Their Measurements", First Edition, McGraw-Hill, New York, (1973).

[44] Bioud, N., Kassali, K., Bouarissa, N., "Thermodynamic Properties of Compressed $\mathrm{CuX}(\mathrm{X}=\mathrm{Cl}, \mathrm{Br})$ Compounds: Ab Initio Study”, Journal of Electronic Materials, 46(4): 2521-2528, (2017).

[45] Khandy, S. A., Gupta, D. C., "Understanding Ferromagnetic Phase Stability, Electronic and Transport Properties of $\mathrm{BaPaO}_{3}$ and $\mathrm{BaNpO}_{3}$ from Ab-Initio Calculations", Journal of Electronic Materials, 46: 5531, (2018).

[46] Khandy, S. A., Gupta, D. C., "Structural, elastic and magneto-electronic properties of half-metallic $\mathrm{BaNpO}_{3}$ perovskite", Materials Chemistry and Physics, 198: 380, (2017).

[47] Bencherif, K., Yakoubi, A., Della, N., Abid, O. M., Khachai, H., Ahmed, R., Khenata, R. Omran, S.B., Gupta, S.K., Murtaza, G., "First principles investigation of the elastic, optoelectronic and thermal properties of XRuSb: $(\mathrm{X}=\mathrm{V}, \mathrm{Nb}, \mathrm{Ta})$ Semi-Heusler Compounds Using the $\mathrm{mBJ}$ Exchange Potential", Journal of Electronic Materials, 45: 3479-3490, (2016).

[48] Liu, X., Fan, H-Q., "Electronic structure, elasticity, Debye temperature and anisotropy of cubic $\mathrm{WO}_{3}$ from first-principles calculation", Royal Society Open Science, 5: 171921, (2018).

[49] Kaderoglu, C., Surucu, G., Erkisi, A., "The investigation of electronic, elastic and vibrational properties of an interlanthanide perovskite: $\mathrm{PrYbO}_{3}$ ", Journal of Electronic Materials, 46: 10, (2017).

[50] Ledbetter, H., Migliori, A., “A general elastic-anisotropy measure”, Journal of Applied Physics, 100: 063516, (2006).

[51] Chang, J., Zhao, G. P., Zhou, X. L., Liu, K., Lu, L.Y., "Structure and mechanical properties of tantalum mononitride under high pressure: A first-principles study", Journal of Applied Physics, 112: 083519, (2012).

[52] Kars Durukan, I., Ciftci, Y. O., "The Effect of pressure on elastic anisotropy, vibration and optical properties of a AgScSi compound”, Journal of Electronic Materials, 48: 4050, (2019).

[53] Mulliken, R. S., "Electronic population analysis on LCAO-MO molecular wave functions", The Journal of Chemical Physics, 2: 1833, (1955). 
[54] Tian, W., Chen, H., "Insight into the mechanical, thermodynamics and superconductor properties of NbRuB via first-principles calculation", Scientific Reports, 6: 1-7, (2016).

[55] Togo, A., Tanaka, I., "First principles phonon calculations in materials science", Scripta Materialia, 108: 1-5, (2015).

[56] Moradi, M., Taheri, N., Rostami, M., "Structural, electronic, magnetic and vibrational properties of half-Heusler NaZrZ (Z = P, As, Sb) compounds", Physics Letters A, 382: 3004-3011, (2018). 